\title{
An anticoagulation protocol for use after congenital cardiac surgery
}

\author{
Asha G. Nair, MD, ${ }^{\text {add }}$ Olubunmi O. Oladunjoye, BS, ${ }^{b}$ Cameron C. Trenor III, MD, MMSc, ${ }^{c, d}$ \\ Meena LaRonde, RN, MSN, CCRN, ${ }^{a}$ Sarah J. van den Bosch, MS, ${ }^{a}$ Lynn A. Sleeper, ScD, ${ }^{\text {a,d }}$ \\ Christina VanderPluym, MD, ${ }^{\mathrm{a}, \mathrm{d}}$ Sitaram M. Emani, MD, ${ }^{\mathrm{b}, \mathrm{e}}$ and John N. Kheir, MD ${ }^{\mathrm{a}, \mathrm{d}}$
}

\begin{abstract}
Background: Patients undergoing surgery for congenital heart disease are at high risk for bleeding as well as thrombosis in the postoperative period. The objective of the study was to describe the design and effects of implementing a standardized unfractionated heparin anticoagulation protocol for children after congenital heart surgery.
\end{abstract}

Methods: We created a tiered guideline for the postoperative management of bleeding and thrombosis. In patients treated with unfractionated heparin, antifactor Xa activity level as well as activated partial thromboplastin time were used for dose titration. Clinical outcomes, including bleeding and thrombosis events, were prospectively collected for 5 months before and after protocol implementation and adjudicated as either minor, clinically relevant nonmajor, or major.

Results: Among 792 surgical patients followed during the study period, a total of 203 patients (87 preimplementation, 116 postimplementation) were treated with therapeutic unfractionated heparin over a total of 1481 patient days. Of these, $28 \%$ were neonates and $35 \%$ were infants ( 29 days to 1 year), with a trend toward fewer neonates and lower Risk Adjustment for Congenital Heart Surgery (RACHS) scores after protocol implementation. Among 1321 time-matched pairs, activated partial thromboplastin time and antifactor Xa activity levels were poorly correlated $\left(r^{2}=0.33\right)$. Clinically relevant bleeding events, which required increased medical care, including blood transfusion, decreased after protocol implementation (4.14 vs 1.62 bleeding events per 100 patient-days; risk ratio, $0.39[0.20-0.75] ; P=.005)$, even after correcting for differences in age and RACHS scores $(P=.006)$. This finding was primarily found after RACHS category 1 to 3 procedures (risk ratio, $0.27[0.10-0.73] ; P=.0099$ ) and in noninfants (risk ratio, $0.25[0.09-0.65] ; P=.005)$. There were no significant differences in the incidences of major bleeding $(P=.88)$ or any thrombosis $(P=.55)$.

Conclusions: The use of a standardized anticoagulation protocol is feasible and might reduce the incidence of bleeding and thrombosis events in postcardiotomy patients. (J Thorac Cardiovasc Surg 2018;156:343-52)

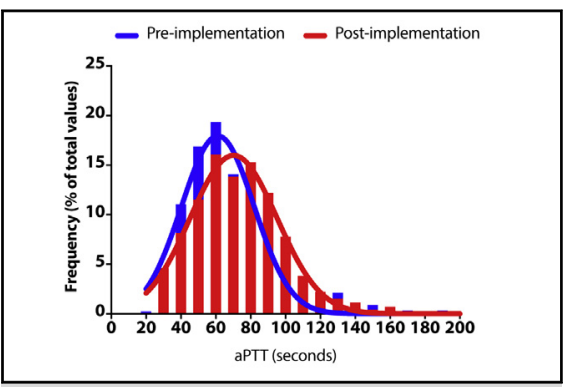

An anticoagulation protocol for postoperative thromboprophylaxis after congenital cardiac surgery decreased the incidence of clinically relevant bleeding events and the fraction of patient-hours above the therapeutic range from $12 \%$ to $4 \%$.

\section{Central Message}

An approach to heparin titration using aPTT as well as anti-Xa levels decreased the incidence of clinically significant bleeding in heparinized patients after congenital heart surgery.

\section{Perspective}

Despite its common use, titration of unfractionated heparin may be guided by either anti$\mathrm{Xa}$ level or partial thromboplastin time. Use of a protocol including both assays decreased the incidence of clinically significant bleeding events, and there was no change in the incidence of thrombosis.

See Editorial Commentary page 353
From the Departments of ${ }^{\mathrm{a} C}$ ardiology and ${ }^{\mathrm{b}}$ Cardiovascular Surgery, and ${ }^{\mathrm{c}}$ Division of Hematology/Oncology, Boston Children's Hospital; and the Departments of ${ }^{\mathrm{d}}$ Pediatrics and ${ }^{\mathrm{e}}$ Surgery, Harvard Medical School, Boston, Mass.

This work was supported by the Gerber Foundation and the Boston Children's Hospital Heart Center Strategic Investment Fund.

Received for publication Feb 21, 2017; revisions received Jan 31, 2018; accepted for publication Feb 15, 2018; available ahead of print April 26, 2018.

Address for reprints: John N. Kheir, MD, Department of Cardiology, Boston Children's Hospital, 300 Longwood Ave, Boston, MA 02115 (E-mail: john.kheir@ childrens.harvard.edu).

$0022-5223 / \$ 36.00$

Copyright (c) 2018 by The American Association for Thoracic Surgery

https://doi.org/10.1016/j.jtcvs.2018.02.106
Patients undergoing surgery for congenital heart disease are at risk for thrombosis as well as bleeding in the postoperative period. Patients with established thromboembolic risk include those with single ventricle cardiac lesions (including those with systemic-pulmonary shunts; $8 \%-12 \%$ incidence of thrombosis ${ }^{1,2}$ ), postoperative

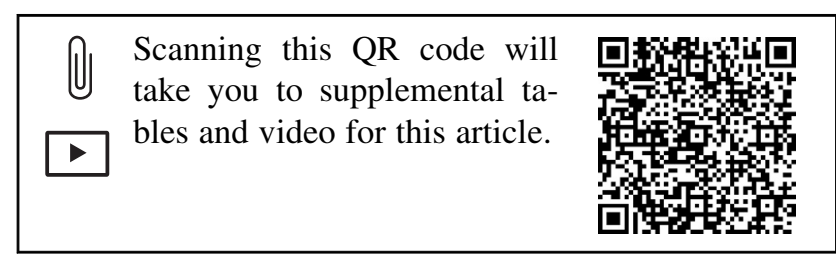




$$
\begin{aligned}
& \text { Abbreviations and Acronyms } \\
& \text { anti-Xa }=\text { antifactor Xa } \\
& \text { aPTT }=\text { activated partial thromboplastin time } \\
& \text { AT }=\text { antithrombin (aka antithrombin III) } \\
& \text { ICU }=\text { intensive care unit } \\
& \text { PD }=\text { patient-days } \\
& \text { RACHS }=\text { Risk Adjustment for Congenital Heart } \\
& \text { Surgery } \\
& \text { UFH }=\text { unfractionated heparin }
\end{aligned}
$$

central venous catheters $\left(40 \%\right.$ incidence of thrombosis $\left.{ }^{3}\right)$, atrial arrhythmias, ${ }^{4}$ and Fontan circulation (17\%-33\% incidence of postoperative thrombosis ${ }^{5,6}$ ). Patients at risk for postoperative bleeding include infants, ${ }^{7,8}$ those undergoing complex procedures, low body weight, repeated sternotomy, and congenital abnormalities. ${ }^{9}$ Postoperative bleeding has been shown to be an independent risk factor for postoperative dialysis, extracorporeal life support, ${ }^{10}$ increased duration of mechanical ventilation, and length of stay. ${ }^{11}$

The management of anticoagulation in this population is complex because of the heightened risk of thrombosis as well as bleeding. Many subspecialists, including cardiologists, cardiac intensivists, cardiac surgeons, neonatologists, pharmacists, and hematologists might contribute to decision-making. Some institutions have formed specialized anticoagulation teams ${ }^{12}$ to guide inpatient and outpatient management. Further complicating anticoagulation management is that no monitoring assay has been shown to predict risk of bleeding, and available assays might yield discrepant values, particularly in newborn infants. For example, unfractionated heparin (UFH), commonly used in the postoperative period, can be monitored using either the activated partial thromboplastin time (aPTT) or using an antifactor Xa activity (anti-Xa) assay. The aPTT is a functional test of coagulation time that might be affected by developmental hemostasis, coagulation factor deficiencies, or circulating coagulation inhibitors (eg, lupus anticoagulants). ${ }^{13}$ The anti-Xa assay chromogenically quantifies the heparin-antithrombin (AT) complex, and is therefore highly dependent upon serum AT levels, ${ }^{14}$ but is otherwise independent of bias from other biological factors. ${ }^{15,16}$ Because AT levels are low in newborn infants, ${ }^{17}$ anti-Xa activity is frequently low in these patients, even in the setting of elevated aPTT. For this reason, some laboratories add AT to all samples before anti-Xa level measurement, following package insert guidance but obscuring AT deficiency in patients. We do not add AT before anti-Xa determination at our institution. Titration of UFH might be according to either assay, and significant disagreement persists in which one to follow.
Few guidelines exist to direct management of coagulation in postsurgical patients, particularly in neonates. Although low molecular weight heparin is commonly used for thromboprophylaxis in the pediatric population, ${ }^{18}$ our protocol describes the use of UFH because of its ability to be administered by continuous infusion (rather than subcutaneous injection) and rapidly titrated in the acute postoperative setting. In this report, we describe a protocol guiding the management of bleeding and thromboprophylaxis on monitoring assay results, as well as the incidence of bleeding and thrombosis in patients undergoing congenital heart surgery at a single institution.

\section{METHODS}

This study was approved by the institutional review board at Boston Children's Hospital. We prospectively recorded bleeding and thrombosis events, as well as all anticoagulation medications and monitoring tests in all consecutive surgical admissions to the Cardiac intensive care unit (ICU) at Boston Children's Hospital from August, 2015 to July, 2016. Patients admitted for medical indications (eg, heart failure) were excluded, as were surgical patients during periods of treatment with a ventricular assist device or extracorporeal membrane oxygenation, who were treated according to separate protocols. Each day, a single investigator prospectively recorded all doses of anticoagulation medications (including UFH infusion rates and changes, enoxaparin, warfarin, aspirin, and clopidogrel), timestamped monitoring laboratory data (including international normalized ratio, aPTT (run in the core laboratory on PTT Automate 5, Diagnostic Stago, Inc, Parsippany, NJ, with silica activator), anti-Xa activity (run in core laboratory without addition of exogenous AT on Stago STAR Evolution, Diagnostic Stago), AT level, and platelet count into a deidentified study record using an automated data export tool (Microstrategy Inc, Tysons Corner, Va), and confirmed by review of the medical record. Bleeding was quantified through abstraction from the medical record as well as bedside discussions with the treating medical team and nurse and adjudicated according to the bleeding and thrombosis definitions outlined below.

\section{Anticoagulation Protocol}

We created a coagulation management protocol that provided coagulation management recommendations for infants and children after cardiac surgery (Figures 1-3). The protocol was on the basis of a systematic review of the available literature, review of best practices in place at other large cardiac centers, and several multidisciplinary meetings including experts in hematology, cardiac surgery, cardiac intensive care, and laboratory medicine. The protocol included 3 phases: acute postoperative management of bleeding, acute postoperative anticoagulation, and long-term inpatient bridge strategy. At the time of ICU admission, the initial anticoagulation approach was decided on the basis of discussion between the attending surgeon and intensivist, who weighed the competing risks of bleeding and thrombosis. Bleeding at ICU admission was classified as mild, moderate, or severe. Patients with severe bleeding were treated with blood product replacement according to documented deficiencies on the basis of either thromboelastography or routine coagulation laboratory values. After hemostasis, the initial anticoagulation strategy (decided at the time of ICU admission) was initiated.

Patients in whom therapeutic anticoagulation was indicated were managed using a guidance table for UFH titration (Figure 4); because of the discrepancies in anti-Xa and aPTT assay results, the table includes a decision matrix, which includes the results of both (ie, patients treated according to the protocol received testing using both assays). During the preimplementation period, UFH titration was performed at the discretion 


\section{Evaluate hemostasis}

\section{Steps upon ICU admission}
1 Admission checklist
1. Define indication for and initial anticoagulation strategy, duration and bridging strategy with surgeon. Identify any special surgical, historical or other considerations affecting anticoagulation. Document in admission and daily note.
2. Identify port to draw heparin levels; use arterial line if no heparin in flush, otherwise identify CVL port with no heparin flush.
3. Send labs
Send PT, INR, PTT, fibrinogen, CBC and TEG for any patient with moderate/severe bleeding or on TEG protocol (ie, any single ventricle patient, any neonate requir- ing $\mathrm{CPB}$, or any patient with $>2$ sternotomies)

2 Define indication for and timing of initial anticoagulation strategy, duration and bridge strategy with surgeon. Common choices below.

\begin{tabular}{|c|c|c|}
\hline $\begin{array}{c}\text { Define initial } \\
\text { anticoagulation strategy }\end{array}$ & $\begin{array}{c}\text { Define duration of } \\
\text { initial strategy }\end{array}$ & $\begin{array}{c}\text { Define } \\
\text { bridge strategy }\end{array}$ \\
\hline Therapeutic heparin & $\begin{array}{l}\text { Until extubated } \\
\text { or } 10 \text { days }\end{array}$ & \multirow{2}{*}{\begin{tabular}{|l|} 
Bridge to nothing \\
Bridge to aspirin \\
Bridge to lovenox \\
\end{tabular}} \\
\hline Intermediate heparin & $\begin{array}{c}\text { Until therapeutic on } \\
\text { ASA }\end{array}$ & \\
\hline \multirow[t]{3}{*}{ Line/prophylactic heparin } & Until IJ removed & \multirow[t]{3}{*}{ Bridge to coumadin } \\
\hline & $\begin{array}{l}\text { Until femoral pulses } \\
\text { return }\end{array}$ & \\
\hline & Until ambulatory & \\
\hline
\end{tabular}

\begin{tabular}{|c|c|c|c|}
\hline Size & Severe bleeding & Moderate bleeding & Mild bleeding \\
\hline$<10 \mathrm{~kg}$ & $>5 \mathrm{~mL} / \mathrm{kg} / \mathrm{h}$ & $3-5 \mathrm{~mL} / \mathrm{kg} / \mathrm{h}$ & $<3 \mathrm{~mL} / \mathrm{kg} / \mathrm{h}$ \\
\hline$>10 \mathrm{~kg}$ & $>100 \mathrm{~mL} / \mathrm{h}$ & $20-100 \mathrm{~mL} / \mathrm{h}$ & $<20 \mathrm{~mL} / \mathrm{h}$ \\
\hline Any & $\begin{array}{c}\text { Requiring PRBC transfusion } \\
\text { for hemodynamics }\end{array}$ & & \\
\hline
\end{tabular}

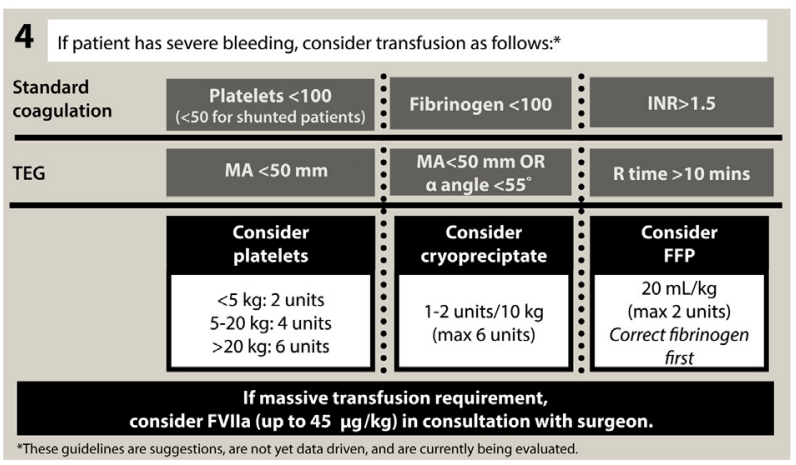

FIGURE 1. The anticoagulation protocol for surgical patients included recommendations for coagulation management during bleeding. Note that specific aPTT goals might vary on the basis of the assay used. aPTT, Activated partial thromboplastin time; $I C U$, intensive care unit; $C V L$, central venous line; $P T$, prothrombin time; $I N R$, international normalized ratio; $P T T$, partial thromboplastin time; $C B C$, complete blood count; $T E G$, thromboelastography; $C P B$, cardiopulmonary bypass; $A S A$, aspirin; $I J$, internal jugular; $P R B C$, packed red blood cell; $M A$, maximal amplitude; Max, maximum; FVIIa, activated factor VIIa.

of the treating team, commonly according to an aPTT titration table (Table E1). After implementation, UFH titration in all patients was performed according to Figure 1, and used the results of anti-Xa level as well as aPTT. This titration matrix, created by the authors, is intended to use anti-Xa whenever possible, but uses aPTT level to dose-limit upward titration of UFH. This was done intentionally to prevent extreme elevations in aPTT, which might increase the risk of bleeding in postsurgical patients, ${ }^{19}$ and is the primary reason that medical patients (who might have a lower intrinsic risk of bleeding) were not included in this protocol. Upon admission, the clinical team identified a site for blood sampling for

\section{Initial anticoagulation} Excludes ECMO, VAD and medical patients

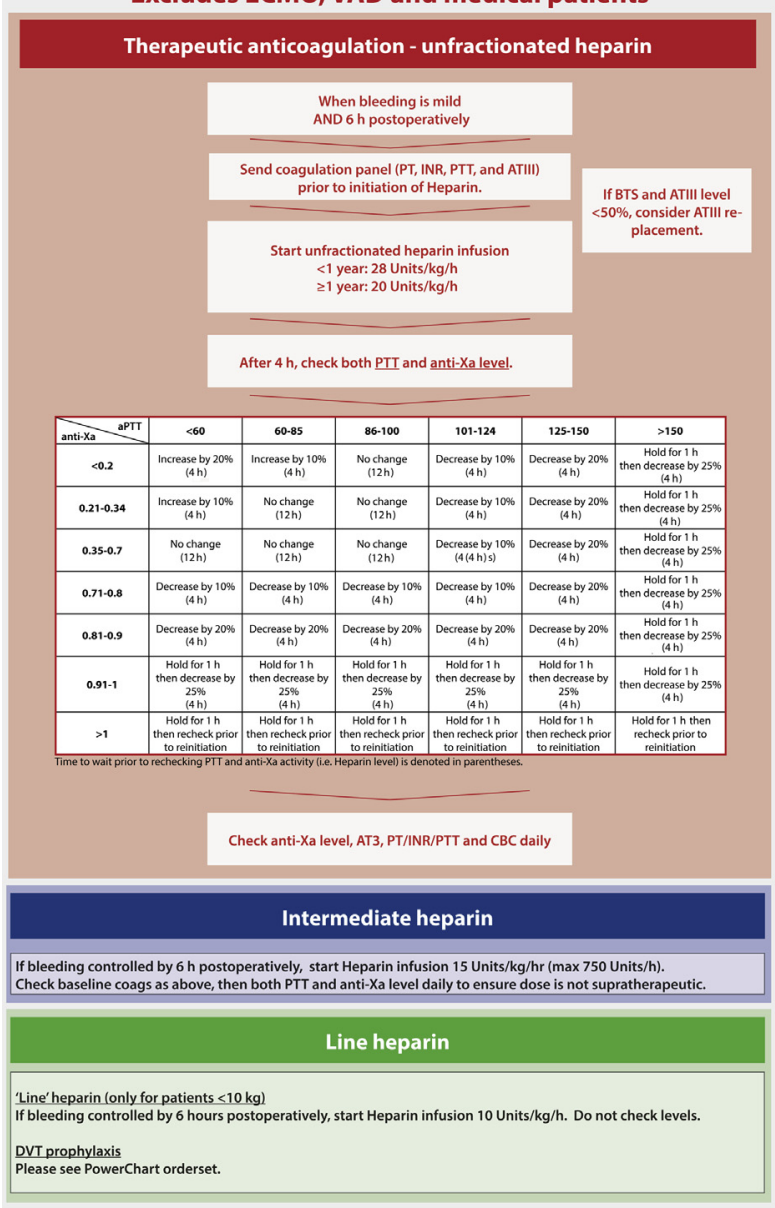

FIGURE 2. The anticoagulation protocol for surgical patients included recommendations for coagulation management for thromboprophylaxis during the acute postoperative period. Note that specific aPTT goals might vary on the basis of the assay used. $a P T T$, Activated partial thromboplastin time; ECMO, extracorporeal membrane oxygenation; $V A D$, ventricular assist device; $P T$, prothrombin time; $I N R$, international normalized ratio; $P T T$, partial thromboplastin time; $A T$, antithrombin; BTS, BlalockTaussig shunt; anti-Xa, antifactor Xa activity; $C B C$, complete blood count; $D V T$, deep vein thrombosis.

anticoagulation laboratory monitoring that did not contain a heparin flush; arterial catheters were preferred. No boluses of UFH were used in either the pre- or postimplementation period in this postsurgical cohort. No routine investigations were performed to investigate discordance between anti$\mathrm{Xa}$ and aPTT assay results.

\section{Protocol Implementation and Monitoring}

Before implementation in February 2016, protocol dissemination included in-person and online (NetLearning, HealthcareSource) educational sessions with the nursing, medical, and surgical physician staff in the cardiac ICU. After implementation, study members rounded daily with medical teams to provide clarity on protocol recommendations, and a phone number was established for questions to be answered ad hoc. A protocol summary was placed on placards at every bedside, as well as in physician and nursing work areas. 


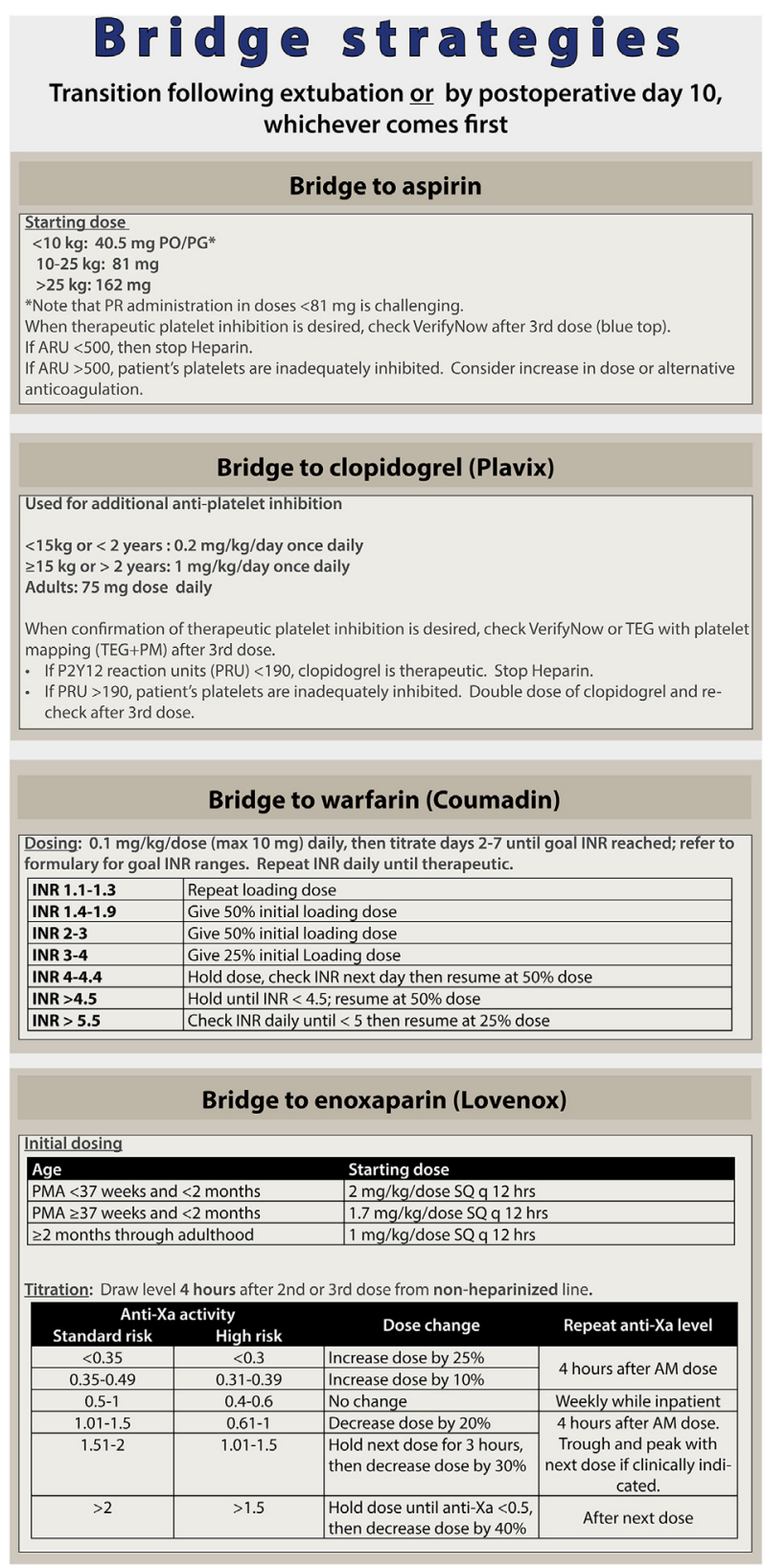

FIGURE 3. The anticoagulation protocol for surgical patients included recommendations for coagulation management during the long-term postoperative period. Note that specific aPTT goals might vary according to the assay used. aPTT, Activated partial thromboplastin time; $P O / P G$, per oral or gastric route; $P R$, per rectum; $A R U$, aspirin response unit; $T E G$, thromboelastography; PM, platelet mapping; PRU, P2Y12 Reaction Unit; max, maximum; INR, international normalized ratio; $P M A$, postmenstrual age; $S Q q$, subcutaneously administered every; anti-Xa, antifactor Xa activity.

After implementation, we assessed compliance with protocol recommendations by comparing medications administered with each patient's laboratory values, time to dose change, and time to next laboratory evaluation. We also monitored compliance with the following documentation metrics by review of the medical record: a successful documentation episode included physician and nursing documentation of the indication for anticoagulation, the intended approach, duration, and bridge strategy.

\section{Therapeutic Anticoagulation Metrics}

We determined the average number of laboratory draws per patient-days (PD), average number of UFH dosing changes per PD, time to target range, and the proportion of patient-hours spent above, below, and within the target range on the basis of review of the database. The target range was defined as laboratory results for which "no change" was prescribed in the relevant protocol.

\section{Bleeding and Thrombosis Definitions}

Bleeding events were defined as listed in Table 1 . These criteria were on the basis of accepted definitions ${ }^{20}$ and modified for the pediatric postcardiotomy population. Events were classified as either major, clinically relevant nonmajor, or minor. Clinically relevant, nonmajor bleeding included any bleeding that was associated with an unscheduled intervention, including a dressing change, laboratory evaluation, or elective transfusion. Blood transfusions took place according to clinician judgement, guided by a unit-wide transfusion protocol that was unchanged during the pre- or postimplementation period (Table E2). Further, events were classified as spontaneous or provoked (ie, procedure-related). For example, a new intracranial hemorrhage was defined as major, spontaneous bleeding. Thoracic drainage for which the patient was not further evaluated or treated was not considered a bleeding event.

Thrombosis definitions are described in Table 2. We did not routinely screen for thrombosis in this study; all identified thrombosis was on the basis of clinically indicated examinations or clinical events. Examples of major thrombosis included aortopulmonary shunt thrombosis or an occlusive arterial thrombus in a central vessel. An incidental, asymptomatic, nonocclusive venous thrombus was classified as minor.

Each bleeding or thrombosis event was recorded, including details of the event, anticoagulation medications, and laboratory values; this record was then adjudicated in blinded fashion according to the definitions described previously by 2 members of the study team. In the event of disagreement, the event was reviewed by an additional member of the research team.

\section{Statistical Methods}

Characteristics of patients studied in the pre- and postprotocol implementation periods were compared using a Fisher exact test for dichotomous variables, a Wilcoxon rank sum test for skewed and ordinal variables, and Student $t$ test for nonskewed continuous variables. Incidence rates for major bleeding and for major thrombosis were calculated using the number of events and the total follow-up time per patient up to date of discharge. Poisson regression was used to compare the incidence rates before and after implementation of the anticoagulation protocol, including a separate analysis controlling for age and Risk Adjustment for Congenital Heart Surgery (RACHS) score. Subgroup analyses according to age and RACHS score were performed without tests of interaction. A generalized linear model with a compound symmetry covariance structure to account for correlated observations was used to assess associations between anti-Xa level as the outcome and aPTT and AT as predictors.

\section{RESULTS}

A total of 792 patients undergoing cardiac surgery from August 2015 to June 2016 were included in this analysis. Three hundred ninety-seven patients in the preimplementation period and 395 in the postimplementation period were followed for a total of $5163 \mathrm{PD}$. A total of 203 patients were treated with therapeutic UFH over a period of 1481 PD. After protocol implementation, there was a nonsignificantly lower proportion of neonates, as well as a lower proportion of patients with RACHS 7 procedures (Table 3 and 


\begin{tabular}{|c|c|c|c|c|c|c|}
\hline $\begin{array}{ll} & \text { aPTT } \\
\end{array}$ & $<60$ & $60-85$ & $86-100$ & $101-124$ & $125-150$ & $>150$ \\
\hline$<0.2$ & $\begin{array}{l}\text { Increase by } 20 \% \\
\text { ( } 4 \text { hours) }\end{array}$ & $\begin{array}{l}\text { Increase by } 10 \% \\
\text { ( } 4 \text { hours) }\end{array}$ & $\begin{array}{l}\text { No change } \\
\text { (12 hours) }\end{array}$ & $\begin{array}{c}\text { Decrease by } 10 \% \\
\text { (4 hours) }\end{array}$ & $\begin{array}{c}\text { Decrease by } 20 \% \\
\text { (4 hours) }\end{array}$ & $\begin{array}{c}\text { Hold for } 1 \text { hour } \\
\text { then decrease by } 25 \% \\
\text { (4 hours) }\end{array}$ \\
\hline $0.21-0.34$ & $\begin{array}{l}\text { Increase by } 10 \% \\
\text { ( } 4 \text { hours) }\end{array}$ & $\begin{array}{l}\text { No change } \\
\text { (12 hours) }\end{array}$ & $\begin{array}{l}\text { No change } \\
\text { (12 hours) }\end{array}$ & $\begin{array}{c}\text { Decrease by } 10 \% \\
\text { (4 hours) }\end{array}$ & $\begin{array}{c}\text { Decrease by } 20 \% \\
\text { (4 hours) }\end{array}$ & $\begin{array}{c}\text { Hold for } 1 \text { hour } \\
\text { then decrease by } 25 \% \\
\text { (4 hours) }\end{array}$ \\
\hline $0.35-0.7$ & $\begin{array}{l}\text { No change } \\
\text { (12 hours) }\end{array}$ & $\begin{array}{l}\text { No change } \\
\text { (12 hours) }\end{array}$ & $\begin{array}{l}\text { No change } \\
\text { (12 hours) }\end{array}$ & $\begin{array}{c}\text { Decrease by } 10 \% \\
\text { (4 hours) }\end{array}$ & $\begin{array}{c}\text { Decrease by } 20 \% \\
\text { (4 hours) }\end{array}$ & $\begin{array}{c}\text { Hold for } 1 \text { hour } \\
\text { then decrease by } 25 \% \\
\text { ( } 4 \text { hours) }\end{array}$ \\
\hline $0.71-0.8$ & $\begin{array}{c}\text { Decrease by } 10 \% \\
\text { ( } 4 \text { hours) }\end{array}$ & $\begin{array}{c}\text { Decrease by } 10 \% \\
\text { (4 hours) }\end{array}$ & $\begin{array}{c}\text { Decrease by } 10 \% \\
\text { (4 hours) }\end{array}$ & $\begin{array}{c}\text { Decrease by } 10 \% \\
\text { (4 hours) }\end{array}$ & $\begin{array}{c}\text { Decrease by } 20 \% \\
\text { (4 hours) }\end{array}$ & $\begin{array}{c}\text { Hold for } 1 \text { hour } \\
\text { then decrease by } 25 \% \\
\text { (4 hours) }\end{array}$ \\
\hline $0.81-0.9$ & $\begin{array}{c}\text { Decrease by } 20 \% \\
\text { ( } 4 \text { hours) }\end{array}$ & $\begin{array}{c}\text { Decrease by } 20 \% \\
\text { (4 hours) }\end{array}$ & $\begin{array}{c}\text { Decrease by } 20 \% \\
\text { (4 hours) }\end{array}$ & $\begin{array}{c}\text { Decrease by } 20 \% \\
\text { (4 hours) }\end{array}$ & $\begin{array}{c}\text { Decrease by } 20 \% \\
\text { (4 hours) }\end{array}$ & $\begin{array}{c}\text { Hold for } 1 \text { hour } \\
\text { then decrease by } 25 \% \\
\text { (4 hours) }\end{array}$ \\
\hline $0.91-1$ & $\begin{array}{c}\text { Hold for } 1 \text { hour } \\
\text { then decrease by } \\
25 \% \\
\text { (4 hours) }\end{array}$ & $\begin{array}{c}\text { Hold for } 1 \text { hour } \\
\text { then decrease by } \\
25 \% \\
(4 \text { hours })\end{array}$ & $\begin{array}{c}\text { Hold for } 1 \text { hour } \\
\text { then decrease by } \\
25 \% \\
\text { (4 hours) }\end{array}$ & \begin{tabular}{|c|} 
Hold for 1 hour \\
then decrease by \\
$25 \%$ \\
(4 hours) \\
\end{tabular} & $\begin{array}{c}\text { Hold for } 1 \text { hour } \\
\text { then decrease by } \\
25 \% \\
\text { (4 hours) }\end{array}$ & $\begin{array}{c}\text { Hold for } 1 \text { hour } \\
\text { then decrease by } 25 \% \\
\text { ( } 4 \text { hours) }\end{array}$ \\
\hline$>1$ & $\begin{array}{l}\text { Hold for } 1 \text { hour } \\
\text { then recheck prior } \\
\text { to reinitiation }\end{array}$ & $\begin{array}{l}\text { Hold for } 1 \text { hour } \\
\text { then recheck prior } \\
\text { to reinitiation }\end{array}$ & $\begin{array}{c}\text { Hold for } 1 \text { hour } \\
\text { then recheck prior } \\
\text { to reinitiation }\end{array}$ & $\begin{array}{c}\text { Hold for } 1 \text { hour } \\
\text { then recheck prior } \\
\text { to reinitiation }\end{array}$ & $\begin{array}{c}\text { Hold for } 1 \text { hour } \\
\text { then recheck prior } \\
\text { to reinitiation }\end{array}$ & $\begin{array}{l}\text { Hold for } 1 \text { hour then } \\
\text { recheck prior to } \\
\text { reinitiation }\end{array}$ \\
\hline
\end{tabular}

FIGURE 4. A titration grid for heparin titration in postoperative patients that incorporates activated partial thromboplastin time as well as anti-Xa activity. The time to rechecking laboratory values is denoted in parentheses. Note that this titration approach was optimized for patients in whom the short-term risk of bleeding was thought to exceed that of thrombosis, and excludes a heparin bolus. anti-Xa, Antifactor Xa activity; aPTT, activated partial thromboplastin time.

Table E3). Survival to ICU discharge was similar between groups $(94.3 \%$ vs $99.1 \% ; P=.13)$.

\section{Protocol Effect on Laboratory Frequency, Blood Transfusions, and Heparin Use}

The average number of blood samples sent for monitoring assays was higher after protocol implementation $(2.14 \pm 1.15$ vs $2.38 \pm 1.13$ laboratory draws per patient per day; $P<.001)$. Assuming a $2-\mathrm{mL}$ blood sample per laboratory draw, this represented $0.58 \pm 0.65 \mathrm{~mL} / \mathrm{kg} / \mathrm{d}$ of UFH monitoring before and $0.90 \pm 0.65 \mathrm{~mL} / \mathrm{kg} / \mathrm{d}$ after protocol implementation for the combined neonate and older infant cohorts $(P=.022)$. Note that aPTT and anti-Xa are simultaneously run on the same aliquot of blood in our core laboratory, and no extra blood was drawn for either test. Accordingly, there was an increase in the mean number of dosing changes per day postprotocol $(2.41 \pm 0.96$ vs $2.94 \pm 0.97$ dosing changes per patient per day; $P=.0001)$. Compliance with protocol recommendations also increased from $58.4 \%$ to $81.1 \%$ of laboratory results after protocol implementation. The number blood transfusions was similar after protocol implementation in patients being treated with UFH ( 0.27 vs 0.14 transfusions per PD; $P=.27$ ).

\section{Protocol Effect on Monitoring Assay Results}

Time to target range was similar between groups (9.2 \pm 0.8 vs $9.3 \pm 0.7$ hours; $P=.95)$. Although the average dose of heparin was similar before and after protocol implementation $(21.8 \pm 6.8$ vs $28.9 \pm 8.2 \mathrm{U} / \mathrm{kg} / \mathrm{h}$; $P=.26$ ), the average aPTT increased after protocol implementation (67 vs 75 seconds; $P<.001$; Figure 5, $A$ ). Among 1321 time-matched pairs, aPTT and anti-Xa levels were found to be poorly correlated $\left(r^{2}=0.33\right)$, and the relationship was similar regardless of age group (Figure 5, B). On the basis of mixed effects modeling, AT was a significant predictor of anti-Xa level $(P<.001)$; when holding aPTT constant, every $10 \%$ increase in AT causes a 0.05 unit increase in anti-Xa level; this means that an anti-Xa level of 0.5 would become 0.75 by correcting AT levels from

TABLE 1. Definitions of bleeding events

\begin{tabular}{|c|c|c|}
\hline Major bleeding & Clinically relevant nonmajor bleeding & Minor bleeding \\
\hline $\begin{array}{l}\text { 1. New or acute on chronic intracranial } \\
\text { hemorrhage (except for germinal matrix } \\
\text { hemorrhage) } \\
\text { 2. Bleeding requiring surgical intervention } \\
\text { 3. Emergent transfusion of blood products for } \\
\text { bleeding with hemodynamic instability } \\
\text { 4. Fatal bleeding }\end{array}$ & $\begin{array}{l}\text { Any overt, actionable signs of hemorrhage that } \\
\text { does not meet the criteria for "major" but does } \\
\text { meet } 1 \text { of the following: } \\
\text { 1. Nonsurgical, medical intervention } \\
\text { (transfusion) } \\
\text { 2. Increased level of care (dressing change) } \\
\text { 3. Prompting evaluation (laboratory or imaging) } \\
\text { 4. Elective transfusion in response to bleeding } \\
\text { event }\end{array}$ & $\begin{array}{l}\text { Bleeding that is not actionable and does not cause } \\
\text { unscheduled performance of studies or any } \\
\text { treatment }\end{array}$ \\
\hline
\end{tabular}


TABLE 2. Classifications of thrombosis events

\begin{tabular}{|c|c|}
\hline Major & Minor \\
\hline $\begin{array}{l}\text { 1. Requiring surgical intervention or } \\
\text { thrombectomy } \\
\text { 2. Requiring systemic or local } \\
\text { administration of thrombolytic agent } \\
\text { 3. Documented thrombus-related arterial } \\
\text { or venous ischemia resulting in } \\
\text { clinically relevant end organ } \\
\text { dysfunction, defined as } 1 \text { or more of } \\
\text { the following: } \\
\text { - Cerebrovascular thrombosis with } \\
\text { or without seizure or neurologic } \\
\text { deficit } \\
\text { - Pulmonary embolism identified on } \\
\text { pulmonary angiogram or computed } \\
\text { tomography scan } \\
\text { - Renal artery or vein thrombus with } \\
\text { elevated creatinine } \\
\text { - Hepatic artery thrombosis } \\
\text { - Mesenteric: documented evidence } \\
\text { of bowel ischemia associated with } \\
\text { mesenteric artery thrombosis } \\
\text { - Limb: evidence of limb ischemia } \\
\text { with occlusive thrombus on } \\
\text { ultrasound }\end{array}$ & $\begin{array}{l}\text { All documented } \\
\text { thrombosis not meeting } \\
\text { criteria for major }\end{array}$ \\
\hline
\end{tabular}

$50 \%$ to $100 \%$. Antithrombin replacement took place in fewer patients after protocol implementation $(21.6 \%$ vs $8.6 \% ; P=.014)$. AT levels were found to be normally distributed in all age groups, and to be similar between neonatal, non-neonate infant, and older children (Figure 5, C). When controlling for AT level, age category (neonate vs infant vs noninfant) was not a significant predictor of anti-Xa. The proportion of time spent above the target range was decreased after protocol implementation $(12.8 \%$ vs $4.4 \%$ of patient-hours), and the time within the target was similar (Figure 6).

\section{Protocol Effect on Bleeding Events}

A total of 677 PD were analyzed before and 804 PD after protocol implementation during treatment with therapeutic UFH. The incidence of clinically relevant bleeding during treatment with UFH decreased from 4.14 to 1.62 events per $100 \mathrm{PD}$ after protocol initiation (risk ratio, 0.39 [0.20$0.75] ; P=.005$; Table 4 ), even after adjustment for age and RACHS score $(P=.006)$. Clinically relevant bleeding events included bleeding from a thoracic drain, surgical or percutaneous catheter site (Table E4), which required a blood transfusion or other medical attention (Table E5). This decrease in bleeding events during therapeutic heparin was primarily found after RACHS category 1 to 3 procedures (risk ratio, 0.27 [0.10-0.73]; $P=.0099$; Table E6), and in noninfants (risk ratio, $0.25[0.09-0.65] ; P=.005$;
Table E7). Overall, the percentage of patients with a major bleeding event during therapeutic heparin was similar for the 2 periods $(2.3 \%$ vs $1.7 \% ; P=.78)$.

\section{Protocol Effects on Thrombosis Events}

The incidence of clinically apparent thrombosis events in patients being treated with therapeutic UFH was similar before and after protocol implementation (risk ratio, 0.76 [0.31-1.86]; $P=.55$; Table 4). Few patients were treated with recombinant factor VIIa $(2.3 \%$ preimplementation, $0 \%$ postimplementation; $P=.18$ ), none of which were contemporaneous with the administration of UFH, and none of the subsequent thrombotic events occurred in these patients. A description of the major thrombosis events is shown in Table E4.

\section{Protocol Effect on Documentation Compliance}

Compliance with documentation metrics improved from $5 \%$ preimplementation to $90 \%$ among physician practitioners and $82 \%$ among nursing staff, postprotocol implementation. Compliance with protocol UFH titration recommendations was $87 \%$.

\section{DISCUSSION}

We describe the effects of an anticoagulation protocol designed for postsurgical cardiac patients. Protocol implementation was associated with a decrease in the incidence of clinically relevant bleeding events that occurred during treatment with therapeutic UFH, even after controlling for important differences between groups in age and RACHS score, with no significant change in the incidence of thrombosis. After protocol implementation, therapeutic anticoagulation monitoring with UFH was more intensive, increasing the number of laboratory checks and dosing changes per day, and decreasing the number of patienthours above the therapeutic range. The increase in blood sampling was an undesirable effect, but was likely related to improved compliance with recommendations for rechecking intervals, which were the same during pre- and postintervention periods. Standardization of anticoagulation practices has the putative benefits of minimizing variability and errors, and has been a national patient safety goal of the Joint Commission (Video 1). ${ }^{21}$

First, although UFH remains commonly used in infants and children, ${ }^{22}$ it remains unclear whether anti-Xa or aPTT should be used as the primary assay to guide UFH titration in neonates and infants. As presented previously, our protocol took a hybrid approach to this issue, using anti-Xa to guide UFH dosing but aPTT to limit UFH dosing. Our institution's formulary allows titration of UFH to either aPTT or anti-Xa levels. Most surgical patients are titrated to aPTT, and titration targets vary according to institution on the basis of the assay used. ${ }^{23}$ In an early study describing anticoagulation in infants and children, a close correlation 
TABLE 3. Characteristics of patients treated with therapeutic UFH before and after protocol implementation

\begin{tabular}{|c|c|c|c|}
\hline Variable & Preimplementation & Postimplementation & $P$ value \\
\hline Patients, $\mathrm{n}$ & 87 & 116 & \\
\hline Patient-days of treatment with therapeutic heparin, $n$ & 677 & 804 & \\
\hline Male sex, $\mathrm{n}(\%)$ & $41(46.6 \%)$ & $50(43.5 \%)$ & .67 \\
\hline Prematurity, n (\%) & $3(3.4 \%)$ & $6(5.3 \%)$ & .73 \\
\hline Known chromosomal abnormality, n (\%) & $0(0 \%)$ & $0(0 \%)$ & $>.9$ \\
\hline Median age at surgery, $y$ & $0.33(0.03-2.37)$ & $0.39(0.10-2.11)$ & .26 \\
\hline \multicolumn{4}{|l|}{ Age at surgery } \\
\hline Neonate $(\leq 28 \mathrm{~d})$ & $30(34.5 \%)$ & $27(23.3 \%)$ & .21 \\
\hline Infant $(29 \mathrm{~d}$ to $1 \mathrm{y})$ & $27(31.0 \%)$ & $44(37.9 \%)$ & \\
\hline Noninfant (>1 y) & $30(34.5 \%)$ & $45(38.8 \%)$ & \\
\hline Median (IQR) length of stay, $d$ & $10.0(5.0-19.5)$ & $9.0(4.0-16.0)$ & .22 \\
\hline \multicolumn{4}{|l|}{ RACHS* } \\
\hline 0 & $4(4.8 \%)$ & $12(11.1 \%)$ & .32 \\
\hline 1 to 3 & $42(50.0 \%)$ & $55(50.9 \%)$ & \\
\hline 4 to 6 & $15(17.9 \%)$ & $20(18.5 \%)$ & \\
\hline 7 & $23(27.4 \%)$ & $21(19.4 \%)$ & \\
\hline \multicolumn{4}{|l|}{ Administration of antiplatelet agents, $\mathrm{n}(\%)$} \\
\hline Aspirin & $37(43 \%)$ & $62(53.4 \%)$ & .12 \\
\hline Clopidogrel & $3(3.4 \%)$ & $0(0 \%)$ & .08 \\
\hline Tirofiban & $1(1.1 \%)$ & $1(0.9 \%)$ & .99 \\
\hline
\end{tabular}

RACHS-7 included orthotopic heart and lung transplantation, the placement or removal of a ventricular assist device, repair of major arteries or veins, and thrombectomy. All $P$ values shown are unadjusted. $I Q R$, Interquartile range; RACHS, Risk Adjustment for Congenital Heart Surgery. *RACHS not categorizable for $\mathrm{n}=11$ patients because age was older than 18 years.

was noted between anti-Xa level and aPTT. ${ }^{24}$ Because of its purity as an assay (including its independence of changes related to developmental hemostasis), the anti-Xa has been the favored assay. The initial description of titrating heparin therapy in children, which featured a small percentage of neonates and infants, reported a low incidence of bleeding complications using an anti-Xa-driven approach. However, more contemporary descriptions of anticoagulation practices in children younger than 6 months of age in which anti-Xa levels (target, 0.35-0.7) are used to titrate UFH therapy describe the incidence of major bleeding events between $11 \%$ and $25 \%$, including bleeding-related deaths. ${ }^{19,25}$ This increased incidence of bleeding might be related to increased surgical complexity, changes in assay reagents and equipment, or differences in UFH preparations. The median dose of UFH used in 1 study was $33 \mathrm{U} / \mathrm{kg} / \mathrm{h}$, and 1 in 6 infants exceeded triple the recommended dose without ever achieving the recommended anti-Xa titer. ${ }^{19}$ Using the aPTT to limit upward titration (a feature of the pre- and postimplementation data), we found a substantially lower incidence of major bleeding events (approximately $2 \%$ ), and no bleeding-related deaths. As others have described, ${ }^{25,26}$ we found the correlation between anti-Xa levels and aPTT levels to be particularly poor in neonates and infants. This has been attributed to lower levels of AT in infants, ${ }^{7,27,28}$ as well as the presence of nonspecific heparin binding proteins, which are abundant in infants, ${ }^{29,30}$ particularly after cardiopulmonary bypass. ${ }^{31}$ Further, deficiencies in procoagulant as well as anticoagulant proteins might also be present in patients with congenital heart disease, ${ }^{6,17}$ altering the usually close correlation between anti-Xa and aPTT present in adults ${ }^{32}$ and older children. ${ }^{24}$ Finally, very high concentrations of heparin might have AT-independent anticoagulant effects (not measured by anti-Xa activity), including heparin cofactor II-mediated inactivation of factor IIa, and AT-independent inhibition of factor $\mathrm{X}$ activation. ${ }^{16}$ Because titration of UFH solely on the basis of anti-Xa activity might lead to the administration of very high doses of UFH and increase the risk of bleeding in postsurgical neonates and infants, functional testing, whether aPTT or other functional tests such as thromboelastography or bleeding time, ${ }^{33}$ should be incorporated into neonate-specific guidelines for UFH titration to limit its upward titration.

Second, this protocol highlights the importance of carefully weighing the competing risks of bleeding and thrombosis in a patient, risks that are likely to change as the patient recovers from surgery. Our protocol was tailored for patients deemed to be at greater immediate risk for bleeding than thrombosis in several ways. No bolus of UFH was used for that reason, although this would significantly decrease the time to therapeutic range. Even without a bolus, our protocol recommended that aPTT 


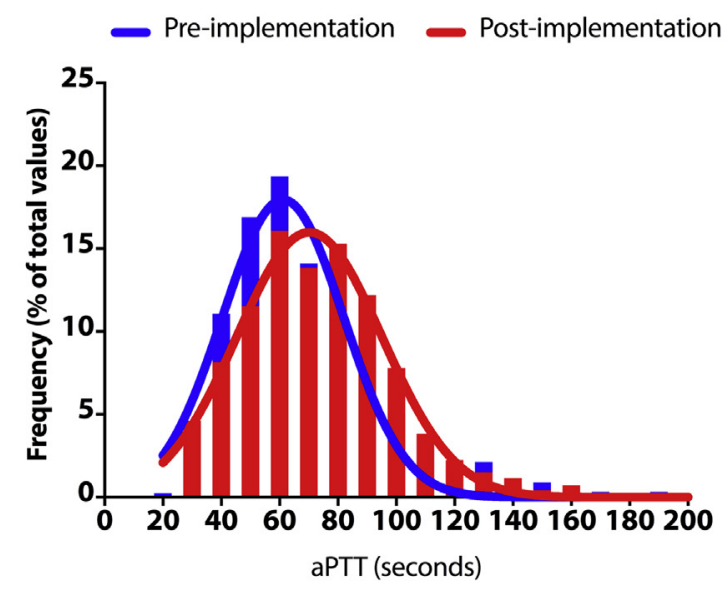

A

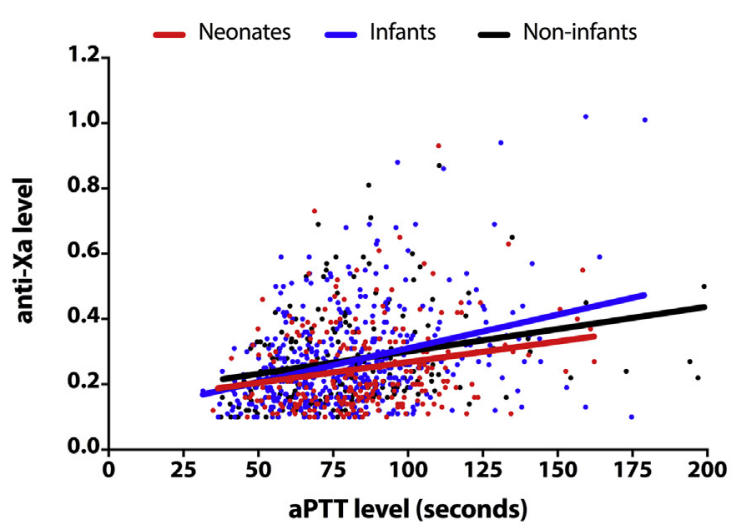

B

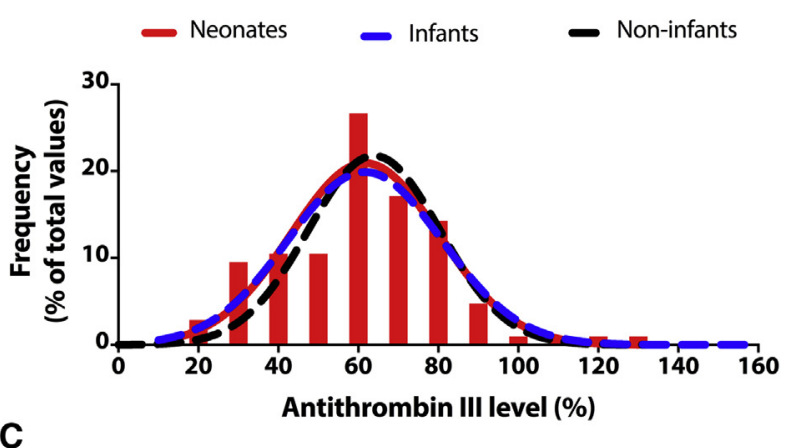

FIGURE 5. A, Histogram of aPTT levels before and after protocol implementation. aPTT levels of $>200$ seconds were similar before and after the protocol (approximately $2.2 \%$ of readings) and were eliminated from the figure for clarity. B, Anti-Xa levels and corresponding aPTT levels in neonates (red), infants (blue), and noninfants (black). There were no agerelated differences in the slope of the relationship, and correlation between the 2 variables was poor (partial $r^{2}=0.33$ ). C, The distribution of antithrombin levels in neonates (red), infants (dotted blue line), and noninfants (dotted black line). Bars shown represent frequency estimates for each $10 \%$ increment for the neonatal group. aPTT, Activated partial thromboplastin time; anti-Xa, antifactor Xa activity.

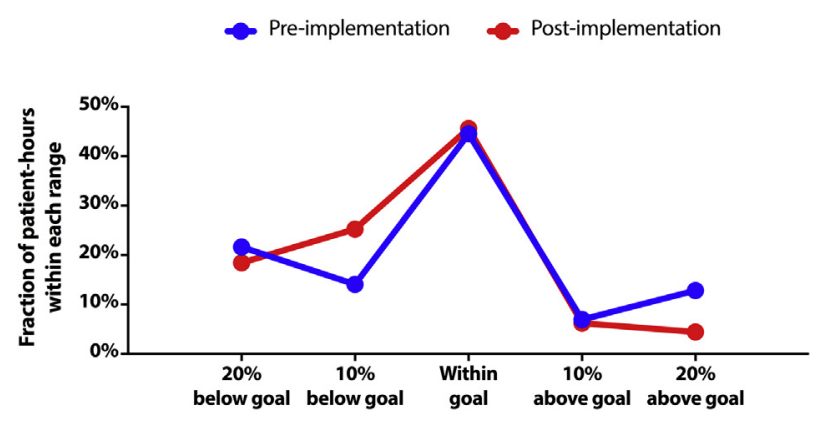

FIGURE 6. Percentage of patient-hours spent below, within, and above the target range, determined according to either aPTT (preprotocol) or aPTT as well as anti-Xa (postprotocol). The number of patient-hours in the $20 \%$ above goal range decreased from $12 \%$ to $4 \%$ after protocol implementation. aPTT, Activated partial thromboplastin time; anti-Xa, antifactor Xa activity.

and anti-Xa levels be checked within 4 hours of initiation of the infusion to ensure that dosing was not supratherapeutic, which did rarely occur. In the absence of a bolus, it would be expected that UFH would take 6 to 8 hours to reach the therapeutic range. As such, this protocol might be less ideal for patients deemed at higher risk for thrombosis than bleeding, including many medical patients, who might benefit from a more aggressive titration strategy and bolus of heparin.

A third challenge common to anticoagulation in neonates and infants is the identification of a site for blood sampling that is free from heparin contamination, often regarded as an important confounder to the results of the aPTT assay. To address this, we took care to identify a single lumen (whether arterial or venous) upon ICU admission to remain heparin-free (ie, no heparin as part of the continuous flush). It has been shown that in adults the incidence of central venous catheter occlusion is similar whether catheters are flushed with heparin or normal saline. ${ }^{34}$ Although it has been suggested that the additional use of heparin in flushes does not prolong the patency of arterial catheters in adults, ${ }^{35}$ at least 1 randomized controlled study of the subject in children suggests that the use of a continuous heparin flush significantly prolongs catheter patency. ${ }^{36}$ These risks are likely to increase in small infants and those with low flow states or cyanosis, all common features of patients recovering from congenital heart surgery. At the least, a discussion regarding the competing risks of catheter nonpatency and arterial thrombosis versus heparin contamination and the need for repeated phlebotomy should take place upon each patient's admission. We found that small infants with femoral arterial catheters were particularly at risk for catheter nonfunction, and in many cases added heparin to the flushes of these patients, making special note of this in the interpretation of assay results. 
TABLE 4. Incidence of bleeding and thrombosis events among all patients while being treated with therapeutic UFH

\begin{tabular}{|c|c|c|c|c|c|c|}
\hline \multicolumn{2}{|c|}{ Number of events (number of patients) } & \multicolumn{2}{|c|}{ Event incidence (per 100 PD) } & \multirow{2}{*}{$\begin{array}{c}\text { Risk ratio after vs before } \\
(95 \% \mathrm{CI})\end{array}$} & \multirow[b]{2}{*}{$P$ value } & \multirow[b]{2}{*}{ Adjusted $P$ value* } \\
\hline Before & After & Before & After & & & \\
\hline \multicolumn{7}{|c|}{ All bleeding days } \\
\hline $54(30)$ & $50(33)$ & 7.98 & 6.22 & $0.78(0.53-1.15)$ & .20 & .21 \\
\hline \multicolumn{7}{|c|}{ Major bleeding days } \\
\hline $2(2)$ & $2(2)$ & 0.30 & 0.25 & $0.84(0.12-5.98)$ & .86 & .88 \\
\hline \multicolumn{7}{|c|}{ Clinically relevant bleeding days } \\
\hline $28(12)$ & $13(10)$ & 4.14 & 1.62 & $0.39(0.20-0.75)$ & .005 & .006 \\
\hline \multicolumn{7}{|c|}{ Clinically relevant and major bleeding days } \\
\hline $30(14)$ & $15(12)$ & 4.43 & 1.87 & $0.42(0.23-0.78)$ & .006 & .007 \\
\hline Any thrombosi & & & & & & \\
\hline $10(9)$ & $9(8)$ & 1.48 & 1.12 & $0.76(0.31-1.86)$ & .55 & .55 \\
\hline \multicolumn{7}{|c|}{ Major thrombosis event } \\
\hline $3(3)$ & $2(2)$ & 0.44 & 0.25 & $0.56(0.09-3.36)$ & .53 & .50 \\
\hline
\end{tabular}

Patients were treated with therapeutic UFH in 677 patient-days during period 1 (before implementation) and 804 PD during period 2 (after implementation). $P D$, Patient-days; $C I$, confidence interval. $* P$ values shown are after adjustment for age and RACHS score; note that $\mathrm{n}=11$ patients were excluded in this adjustment because of unclassifiable RACHS scores (age $>18$ years)

\section{Limitations}

There are several limitations to our work. The first is that although we prospectively gathered data and adjudicated the end points in real time, we did not empirically screen (eg, using ultrasound) for the presence of thrombosis, such that the events reported represent only clinically apparent and major thrombotic events. A decrease in even a single event would be considered clinically important. The incidence of clinically covert thrombosis, particularly in infants with central venous catheters and congenital heart disease, is higher than described in this report. The effect of our anticoagulation approach on the incidence of clinically silent thrombosis is uncertain. Second, there was some education and focus on anticoagulation in the months leading up to protocol implementation (ie, during the control, preimplementation period), which might have improved

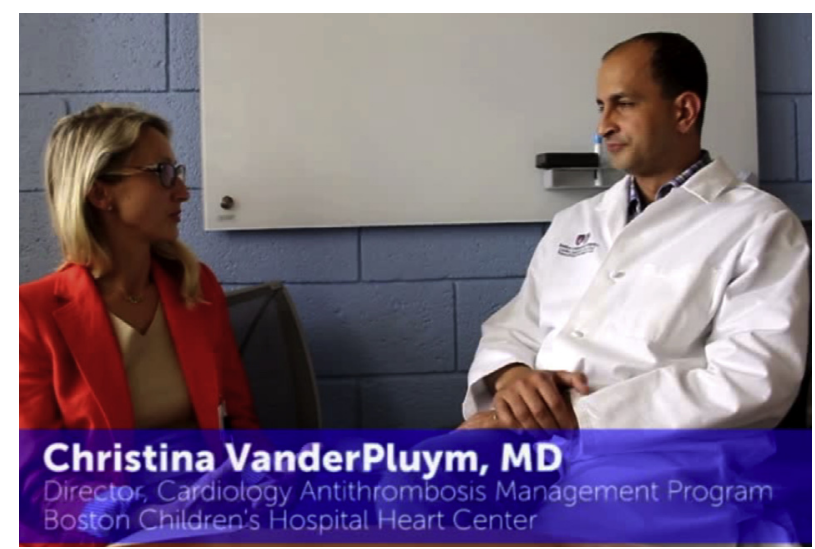

VIDEO 1. Two of the authors discuss the context of this study, the reasoning behind monitoring aPTT as well as anti-Xa levels, and the limitations of this study. Video available at: https://www.jtcvs.org/article/ S0022-5223(18)30930-9/fulltext. practice compared with another randomly chosen period of time. Third is the relatively time-limited period of data capture. Although the number of patients we studied exceeds that of most contemporary pediatric studies, we were underpowered to detect small effect sizes on thrombosis events. Because the observed preimplementation thrombosis rate was 1.48 per $100 \mathrm{PD}$ and because of our study size, we had $80 \%$ power to detect a difference only if the postimplementation thrombosis rate was 0.15 per 100 PD or lower. Fourth, the population we studied was a consecutive sample that represented a heterogenous cohort of heart disease, hematocrit, oxyhemoglobin saturation, and other patient-level factors, which likely affect coagulation status but were not studied as covariates. Finally, changes in laboratory parameters noted after protocol implementation (eg, partial thromboplastin time) might have been in part related to differences in assay or UFH reagent lots rather than the protocol itself.

\section{CONCLUSIONS}

The use of a standardized anticoagulation protocol is feasible and might reduce the incidence of bleeding and thrombosis events in postcardiotomy patients. The exclusive use of anti-Xa alone to titrate UFH in postsurgical children, particularly in neonates and infants, might increase the incidence of major bleeding events and should be carefully considered.

\section{Conflict of Interest Statement}

Authors have nothing to disclose with regard to commercial support.

The authors thank the nursing staff, nurse educators, cardiac anesthesia staff, and coagulation laboratory members of the 
Cardiac Intensive Care Unit at Boston Children's Hospital for assistance with this work, as well as Carlo Brugnara and Ellis Neufeld for helpful insights.

\section{References}

1. Heidari-Bateni G, Norouzi S, Hall M, Brar A, Eghtesady P. Defining the best practice patterns for the neonatal systemic-to-pulmonary artery shunt procedure. J Thorac Cardiovasc Surg. 2014;147:869-73.e3.

2. Ergul Y, Kiplapinar N, Tanidir IC, Ozturk E, Guzeltas A, Haydin S, et al. Role of thrombophilia factors in acute systemic-pulmonary shunt obstruction. Pediatr Int. 2015;57:1072-7.

3. Anton N, Cox PN, Massicotte MP, Chait P, Yasui Y, Dinyari PM, et al. Heparinbonded central venous catheters do not reduce thrombosis in infants with congenital heart disease: a blinded randomized, controlled trial. Pediatrics. 2009;123: e453-8.

4. Khairy P, Aboulhosn J, Broberg CS, Cohen S, Cook S, Dore A, et al. Thromboprophylaxis for atrial arrhythmias in congenital heart disease: a multicenter study. Int J Cardiol. 2016;223:729-35.

5. Giglia TM, Massicotte MP, Tweddell JS, Barst RJ, Bauman M, Erickson CC, et al. Prevention and treatment of thrombosis in pediatric and congenital heart disease: a scientific statement from the American Heart Association. Circulation. 2013;128:2622-703.

6. Odegard KC, McGowan FX Jr, DiNardo JA, Castro RA, Zurakowski D, Connor CM, et al. Coagulation abnormalities in patients with single-ventricle physiology precede the Fontan procedure. J Thorac Cardiovasc Surg. 2002; 123:459-65.

7. Andrew M, Paes B, Milner R, Johnston M, Mitchell L, Tollefsen DM, et al. Development of the human coagulation system in the full-term infant. Blood. 1987;70:165-72.

8. Sola-Visner M. Platelets in the neonatal period: developmental differences in platelet production, function, and hemostasis and the potential impact of therapies. Hematology Am Soc Hematol Educ Program. 2012;2012:506-11.

9. Brenner MK, Clarke S, Mahnke DK, Simpson P, Bercovitz RS, TomitaMitchell A, et al. Effect of 22q11.2 deletion on bleeding and transfusion utilization in children with congenital heart disease undergoing cardiac surgery. Pediatr Res. 2015;79:318-24.

10. Guzzetta NA, Allen NN, Wilson EC, Foster GS, Ehrlich AC, Miller BE. Excessive postoperative bleeding and outcomes in neonates undergoing cardiopulmonary bypass. Anesth Analg. 2015;120:405-10.

11. Kipps AK, Wypij D, Thiagarajan RR, Bacha EA, Newburger JW. Blood transfusion is associated with prolonged duration of mechanical ventilation in infants undergoing reparative cardiac surgery. Pediatr Crit Care Med. 2011;12:52-6.

12. Murray JM, Hellinger A, Dionne R, Brown L, Galvin R, Griggs S, et al. Utility of a dedicated pediatric cardiac anticoagulation program: the Boston Children's Hospital experience. Pediatr Cardiol. 2015;36:842-50.

13. Ignjatovic V, Furmedge J, Newall F, Chan A, Berry L, Fong C, et al. Age-related differences in heparin response. Thromb Res. 2006;118:741-5.

14. Price EA, Jin J, Nguyen HM, Krishnan G, Bowen R, Zehnder JL. Discordant aPTT and anti-Xa values and outcomes in hospitalized patients treated with intravenous unfractionated heparin. Ann Pharmacother. 2013;47:151-8.

15. Olson JD, Arkin CF, Brandt JT, Cunningham MT, Giles A, Koepke JA, et al. College of American Pathologists Conference XXXI on laboratory monitoring of anticoagulant therapy: laboratory monitoring of unfractionated heparin therapy. Arch Pathol Lab Med. 1998;122:782-98.

16. Garcia DA, Baglin TP, Weitz JI, Samama MM; American College of Chest Physicians. Parenteral anticoagulants: antithrombotic therapy and prevention of thrombosis, 9th ed: American College of Chest Physicians evidence-based clinical practice guidelines. Chest. 2012;141(2 Suppl):e24S-43S.

17. Odegard KC, Zurakowski D, Hornykewycz S, DiNardo JA, Castro RA, Neufeld EJ, et al. Evaluation of the coagulation system in children with twoventricle congenital heart disease. Ann Thorac Surg. 2007;83:1797-803.
18. Faustino EVS, Hanson S, Spinella PC, Tucci M, O’Brien SH, Nunez AR, et al. A multinational study of thromboprophylaxis practice in critically ill children. Crit Care Med. 2014;42:1232-40.

19. Schechter T, FIinkelstein Y, Ali M, Kahr WH, Williams S, Chan AK, et al. Unfractionated heparin dosing in young infants: clinical outcomes in a cohort monitored with anti-factor Xa levels. Journal Thromb Haemost. 2012;10:368-74.

20. Schulman S, Angeras U, Bergqvist D, Eriksson B, Lassen MR, Fisher W, et al. Definition of major bleeding in clinical investigations of antihemostatic medicinal products in surgical patients. J Thromb Haemost. 2010;8:202-4.

21. The Joint Commission. 2017 Joint Commission Patient Safety Goals. Available at: https://www.jointcommission.org/assets/1/6/2017_NPSG_HAP_ ER.pdf. Accessed April 19, 2018.

22. Kuhle S, Massicotte P, Chan A, Adams M, Abdolell M, de Veber G, et al. Systemic thromboembolism in children. Data from the 1-800-NO-CLOTS consultation service. Thromb Haemost. 2004;92:722-8.

23. Brill-Edwards P, Ginsberg JS, Johnston M, Hirsh J. Establishing a therapeutic range for heparin therapy. Ann Intern Med. 1993;119:104-9.

24. Andrew M, Marzinotto V, Massicotte P, Blanchette V, Ginsberg J, BrillEdwards P, et al. Heparin therapy in pediatric patients: a prospective cohort study. Pediatr Res. 1994;35:78-83.

25. Kuhle S, Eulmesekian P, Kavanagh B, Massicotte P, Vegh P, Mitchell LG. A clinically significant incidence of bleeding in critically ill children receiving therapeutic doses of unfractionated heparin: a prospective cohort study. Haematologica. 2007;92:244-7.

26. Chan AK, Black L, Ing C, Brandão LR, Williams S. Utility of aPTT in monitoring unfractionated heparin in children. Thromb Res. 2008;122:135-6.

27. Andropoulos DB, Fraser CD. Antithrombin levels during pediatric cardiopulmonary bypass: key to changing a decades-old paradigm for anticoagulation? J Thorac Cardiovasc Surg. 2016;151:305-6.

28. Manlhiot C, Gruenwald CE, Holtby HM, Brandão LR, Chan AK, Van Arsdell GS, et al. Challenges with heparin-based anticoagulation during cardiopulmonary bypass in children: impact of low antithrombin activity. J Thorac Cardiovasc Surg. 2016;151:444-50.

29. Ignjatovic V, Straka E, Summerhayes R, Monagle P. Age-specific differences in binding of heparin to plasma proteins. J Thromb Haemost. 2010;8:1290-4.

30. Young E, Prins M, Levine MN, Hirsh J. Heparin binding to plasma proteins, an important mechanism for heparin resistance. Thromb Haemost. 1992;67:639-43.

31. Teoh KH, Young E, Bradley CA, Hirsh J. Heparin binding proteins. Contribution to heparin rebound after cardiopulmonary bypass. Circulation. 1993;88:II420I425.

32. Byun JH, Jang IS, Kim JW, Koh EH. Establishing the heparin therapeutic range using aPTT and anti-Xa measurements for monitoring unfractionated heparin therapy. Blood Res. 2016;51:171.

33. Brisset AC, Ferrández A, Krause M, Rathbun S, Marlar R, Korte W. The PiCT test is a reliable alternative to the activated partial thromboplastin time in unfractionated heparin therapy management: results from a multicenter study. J Thromb Haemost. 2016;14:2187-93.

34. López-Briz E, Ruiz Garcia V, Cabello JB, Bort-Marti S, Carbonell Sanchis R, Burls A. Heparin versus $0.9 \%$ sodium chloride intermittent flushing for prevention of occlusion in central venous catheters in adults. Cochrane Database Syst Rev. 2014;31:CD008462.

35. Robertson-Malt S, Malt GN, Farquhar V, Greer W. Heparin versus normal saline for patency of arterial lines. Cochrane Database Syst Rev. 2014;20: CD007364.

36. de Neef M, Heijboer H, van Woensel JB, de Haan RJ. The efficacy of heparinization in prolonging patency of arterial and central venous catheters in children: a randomized double-blind trial. Pediatr Hematol Oncol. 2002;19: 553-60.

Key Words: anticoagulation, heparin, bleeding, thrombosis, congenital heart disease 
TABLE E1. Titration protocol for UFH before protocol implementation

\begin{tabular}{lll}
\hline aPTT $(\mathbf{s})$ & \multicolumn{1}{c}{ Dosage adjustment } & Time to repeat aPTT \\
\hline$<50$ & Give 50 U/kg bolus and increase infusion rate by $10 \% *$ & 4 hours after change \\
50 to 59 & Increase infusion rate by $10 \%$ & 4 hours after change \\
\hline 60 to 85 & No change & Next day \\
85 to 95 & Decrease infusion rate by $10 \%$ & 4 hours after change \\
96 to 120 & Hold infusion for 30 min and decrease infusion rate by $10 \%$ & 4 hours after change \\
$>120$ & Hold infusion for 60 min and decrease infusion rate by $15 \%$ & 4 hours after change \\
\hline
\end{tabular}

This table was available on our institution's formulary page. aPTT, Activated partial thromboplastin time. *Because of the surgical nature of the patients in this study, the bolus of UFH was never administered as part of this protocol per clinician discretion.

TABLE E2. Cardiac intensive care unit transfusion protocol

\begin{tabular}{lcc}
\hline \multicolumn{1}{c}{ Age } & $\begin{array}{c}\text { Cyanotic congenital } \\
\text { heart disease }\end{array}$ & $\begin{array}{c}\text { Acyanotic congenital } \\
\text { heart disease }\end{array}$ \\
\hline Neonate $(\leq 28 \mathrm{~d})$ & $37 \%$ & $33 \%$ \\
Infant $(29 \mathrm{~d}$ to $1 \mathrm{y})$ & $37 \%$ & $30 \%$ \\
$>1 \mathrm{y}$ & $37 \%$ & $30 \%$ \\
\hline
\end{tabular}

The goal transfusion volume is $15 \mathrm{~mL} / \mathrm{kg}$ (up to $15 \mathrm{~kg}$ ) with goal hematocrit as specified above. Note that the protocol was in place and unchanged throughout the duration of the study period (ie, pre- or postprotocol). 
TABLE E3. Description of procedures that patients received who were subsequently treated with therapeutic UFH before and after implementation of an anticoagulation protocol

\begin{tabular}{lcc}
\hline \multicolumn{1}{c}{ Primary procedure } & Before protocol & After protocol \\
\hline Univentricular heart disease & & $7(8.0 \%)$ \\
$\quad$ Stage 1 procedure & $5(5.7 \%)$ & $12(10.3 \%)$ \\
Bidirectional cavopulmonary anastomosis & $7(8.0 \%)$ & $5(4.3 \%)$ \\
$\quad$ Fontan & $6(6.9 \%)$ & $7(6.0 \%)$ \\
Arterial switch operation & $8(9.2 \%)$ & $7(6.0 \%)$ \\
Tetralogy of Fallot repair & $15(17.2 \%)$ & $9(7.8 \%)$ \\
Atrioventricular valve repair or replacement & $8(9.2 \%)$ & $16(13.8 \%)$ \\
Aortic or pulmonary valve repair or replacement & $16(18.4 \%)$ & $16(13.8 \%)$ \\
Atrial or ventricular septal defect or complete atrioventricular canal repair & $4(4.6 \%)$ & $17(14.7 \%)$ \\
Left ventricular obstructive lesion (eg, aortic arch reconstruction or aortic valve repair) & $3(3.4 \%)$ & $11(9.5 \%)$ \\
Pulmonary vein stenosis & $8(9.2 \%)$ & $4(3.4 \%)$ \\
Other & $12(10.3 \%)$ \\
\hline
\end{tabular}

TABLE E4. Description of the major and clinically relevant nonmajor bleeding and thrombosis events in patients during treatment with unfractionated heparin before and after protocol implementation

\begin{tabular}{|c|c|c|}
\hline & Preprotocol & Postprotocol \\
\hline \multicolumn{3}{|l|}{ Major bleeding events } \\
\hline $\begin{array}{l}\text { Surgical site bleeding requiring surgical intervention (ie, thoracic } \\
\text { exploration) }\end{array}$ & $1(1)$ & 0 \\
\hline \multicolumn{3}{|l|}{ Nonsurgical site bleeding requiring surgical intervention } \\
\hline Line entry site bleeding & 0 & $1(1)$ \\
\hline Intracranial hemorrhage & $1(1)$ & $1(1)$ \\
\hline Total & $2(2)$ & $2(2)$ \\
\hline \multicolumn{3}{|l|}{ Clinically relevant (nonmajor) bleeding events } \\
\hline Thoracic drainage tube or wound site bleeding & $14(11)$ & $7(6)$ \\
\hline Line entry site bleeding (eg, previous cardiac catheterization site) & $7(2)$ & $4(4)$ \\
\hline Airway bleeding & $5(3)$ & $1(1)$ \\
\hline Gastrointestinal bleeding & $2(2)$ & $1(1)$ \\
\hline Total & $28(12)$ & $13(10)$ \\
\hline \multicolumn{3}{|l|}{ Major thrombosis events } \\
\hline Cerebrovascular thrombosis (eg, venous sinus thrombus) & $1(1)$ & 0 \\
\hline Blalock-Taussig shunt thrombosis & $2(2)$ & $1(1)$ \\
\hline Intracardiac thrombus (not CVL-related) & 0 & $1(1)$ \\
\hline Total & $3(3)$ & $2(2)$ \\
\hline \multicolumn{3}{|l|}{ Minor thrombosis events } \\
\hline Occlusive arterial thrombosis & $2(2)$ & $3(3)$ \\
\hline Occlusive venous thrombosis & $1(1)$ & $1(1)$ \\
\hline Nonocclusive venous thrombosis & $3(2)$ & $2(2)$ \\
\hline Intravascular thrombosis of shunt material (eg, Sano conduit) & $1(1)$ & 0 \\
\hline Total & $7(6)$ & $6(6)$ \\
\hline
\end{tabular}

Results represent events with number of patients shown in parentheses. Note that events are not mutually exclusive such that a single patient might have had more than 1 event. $C V L$, Central venous line. 
TABLE E5. Interventions associated with clinically relevant, nonmajor bleeding events

\begin{tabular}{lcc}
\hline \multicolumn{1}{c}{ Associated interventions } & Preprotocol & Postprotocol \\
\hline Blood transfusion & 7 & 4 \\
Discontinuation of UFH infusion & 6 & 5 \\
\hline $\begin{array}{l}\text { Applied pressure and/or dressing } \\
\text { change }\end{array}$ & 8 & 3 \\
$\begin{array}{l}\text { Additional suctioning of tracheal tube } \\
\text { for airway bleeding }\end{array}$ & 3 & 0 \\
\hline Additional laboratory monitoring & 4 & 1 \\
\hline
\end{tabular}

UFH, Unfractionated heparin.

TABLE E6. Summary of bleeding and thrombosis rates divided by RACHS score

\begin{tabular}{|c|c|c|c|c|}
\hline & \multicolumn{2}{|c|}{ Event incidence rate (per 100 PD on therapeutic UFH) } & \multirow{2}{*}{$\begin{array}{c}\text { Risk ratio preprotocol vs } \\
\text { postprotocol }(95 \% \text { CI })\end{array}$} & \multirow[b]{2}{*}{$P$ value } \\
\hline & Before & After & & \\
\hline \multicolumn{5}{|l|}{ All bleeding days } \\
\hline RACHS 0 & 12.12 & 5.88 & $0.49(0.11-2.17)$ & .34 \\
\hline RACHS 1 to 3 & 10.53 & 7.53 & $0.72(0.42-1.20)$ & .21 \\
\hline RACHS 4 to 6 & 4.23 & 4.89 & $1.15(0.46-2.87)$ & .75 \\
\hline RACHS 7 & 5.67 & 3.43 & $0.60(0.21-1.74)$ & .35 \\
\hline \multicolumn{5}{|c|}{ Major bleeding days } \\
\hline RACHS 0 & 0 & 1.96 & * & * \\
\hline RACHS 1 to 3 & 0.33 & 0.30 & $0.92(0.05-14.64)$ & .95 \\
\hline RACHS 4 to 6 & 0.53 & 0.00 & * & * \\
\hline RACHS 7 & 0 & 0 & * & * \\
\hline \multicolumn{5}{|c|}{ Clinically relevant bleeding days } \\
\hline RACHS 0 & 3.03 & 0 & * & $*$ \\
\hline RACHS 1 to 3 & 5.59 & 1.51 & $0.27(0.10-0.73)$ & .0099 \\
\hline RACHS 4 to 6 & 3.17 & 2.22 & $0.70(0.21-2.29)$ & .56 \\
\hline RACHS 7 & 2.84 & 0.57 & $0.20(0.02-1.80)$ & .15 \\
\hline \multicolumn{5}{|c|}{ Clinically relevant and major bleeding days } \\
\hline RACHS 0 & 3.03 & 1.96 & $0.65(0.04-10.34)$ & .75 \\
\hline RACHS 1 to 3 & 5.92 & 1.81 & $0.31(0.12-0.77)$ & .0118 \\
\hline RACHS 4 to 6 & 3.70 & 2.22 & $0.60(0.19-1.89)$ & .38 \\
\hline RACHS 7 & 2.84 & 0.57 & $0.20(0.02-1.80)$ & .15 \\
\hline \multicolumn{5}{|l|}{ Any thrombosis } \\
\hline RACHS 0 & 6.06 & 3.92 & $0.65(0.09-4.59)$ & .66 \\
\hline RACHS 1 to 3 & 0.66 & 1.51 & $2.28(0.44-11.80)$ & .32 \\
\hline RACHS 4 to 6 & 1.06 & 0.44 & $0.42(0.03-4.63)$ & .48 \\
\hline RACHS 7 & 2.84 & 0.57 & $0.20(0.02-1.80)$ & .15 \\
\hline \multicolumn{5}{|l|}{ Major thrombosis } \\
\hline RACHS 0 & 0 & 1.96 & $*$ & * \\
\hline RACHS 1 to 3 & 0 & 0 & $*$ & * \\
\hline RACHS 4 to 6 & 0.53 & 0 & $*$ & * \\
\hline RACHS 7 & 1.42 & 0.57 & $0.40(0.04-4.44)$ & .46 \\
\hline
\end{tabular}

$P D$, Patient days; $U F H$, unfractionated heparin; $C I$, confidence interval; $R A C H S$, Risk Adjustment for Congenital Heart Surgery. *Denotes an inestimable risk ratio and $P$ value due to insufficient event rates in 1 or more groups. 
TABLE E7. Incidence of bleeding and thrombosis events among neonates (0-28 days), infants (29 days to 12 months of age), and noninfants (>12 months)

\begin{tabular}{|c|c|c|c|c|}
\hline & \multicolumn{2}{|c|}{ Event incidence rate (per 100 PD) } & \multirow[b]{2}{*}{ Risk ratio before vs after $(95 \%$ CI $)$} & \multirow[b]{2}{*}{$P$ value } \\
\hline & Before protocol & After protocol & & \\
\hline \multicolumn{5}{|c|}{ All bleeding days } \\
\hline Neonate & 3.74 & 4.47 & $1.19(0.51-2.76)$ & .68 \\
\hline Infant & 4.76 & 6.81 & $1.43(0.68-2.96)$ & .33 \\
\hline Noninfant & 19.08 & 7.39 & $0.38(0.20-0.74)$ & .0038 \\
\hline \multicolumn{5}{|c|}{ Major bleeding days } \\
\hline Neonate & 0 & 0.41 & $*$ & $*$ \\
\hline Infant & 0.48 & 0.26 & $0.55(0.03-8.79)$ & .67 \\
\hline Noninfant & 0.58 & 0 & $*$ & $*$ \\
\hline \multicolumn{5}{|c|}{ Clinically relevant bleeding days } \\
\hline Neonate & 1.02 & 1.63 & $1.59(0.36-7.12)$ & .54 \\
\hline Infant & 2.38 & 1.05 & $0.44(0.12-1.64)$ & .22 \\
\hline Noninfant & 11.56 & 2.84 & $0.25(0.09-0.65)$ & .005 \\
\hline \multicolumn{5}{|c|}{ Clinically relevant and major bleeding days } \\
\hline Neonate & 1.02 & 2.03 & $1.99(0.48-8.33)$ & .35 \\
\hline Infant & 2.86 & 1.31 & $0.45(0.14-1.50)$ & .19 \\
\hline Noninfant & 12.14 & 2.84 & $0.23(0.09-0.62)$ & .0035 \\
\hline \multicolumn{5}{|c|}{ Any thrombosis } \\
\hline Neonate & 2.04 & 1.63 & $0.80(0.23-2.82)$ & .73 \\
\hline Infant & 1.43 & 1.31 & $0.91(0.21-3.84)$ & .90 \\
\hline Noninfant & 0.580 .30 & 0 & $*$ & $*$ \\
\hline \multicolumn{5}{|c|}{ Major thrombosis } \\
\hline Neonate & 0.68 & 0.41 & $0.60(0.05-6.59)$ & .67 \\
\hline Infant & 0 & 0.26 & $*$ & * \\
\hline Noninfant & 0.58 & 00.41 & * & * \\
\hline
\end{tabular}

$P D$, Patient-days; $C I$, confidence interval. *Denotes an inestimable risk ratio and $P$ value due to insufficient event rates in 1 or more groups. 